\title{
LDL-C: lower is better for longer-even at low risk
}

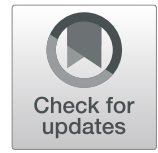

Peter E. Penson ${ }^{1,2,3}$, Matteo Pirro ${ }^{4}$ and Maciej Banach ${ }^{5,6,7^{*}}$ (D)

\begin{abstract}
Background: Low-density lipoprotein cholesterol (LDL-C) causes atherosclerotic disease, as demonstrated in experimental and epidemiological cohorts, randomised controlled trials, and Mendelian randomisation studies.

Main text: There is considerable inconsistency between existing guidelines as to how to effectively manage patients at low overall risk of cardiovascular disease (CVD) who have persistently elevated levels of LDL-C. We propose a step-by-step practical approach for the management of cardiovascular risks in individuals with low $(<1 \%)$ 10-year risk of CVD, and elevated (>140 mg/dL, $3.6 \mathrm{mmol} / \mathrm{L}) \mathrm{LDL}-\mathrm{C}$. The strategy proposed is based on the level of adherence to lifestyle interventions (LSI), and in case of non-adherence, stepwise practical management, including lipid-lowering therapy, is recommended to achieve a target $L D L-C$ levels $(<115 \mathrm{mg} / \mathrm{dL}, 3.0 \mathrm{mmol} / \mathrm{L})$.
\end{abstract}

Conclusions: Further studies are necessary to answer the questions on the long-term efficacy, safety, and costeffectiveness of the suggested approach. This is critical, considering the ever-increasing numbers of such low-risk patients seen in clinical practice.

Keywords: Cardiovascular disease, Ezetimibe, Low risk, Risk stratification, Statins

\section{Background}

Low-density lipoprotein cholesterol (LDL-C) causes atherosclerotic disease. This fact has been repeatedly demonstrated in experimental studies, epidemiological cohorts, randomised clinical trials of LDL-C lowering drugs, and studies employing Mendelian randomisation [1]. Notably, the gradient of the relationship between LDL-C and outcomes of atherosclerotic disease becomes steeper with increasing duration of follow-up (in epidemiological studies) and treatment (in intervention trials). From this, it can be concluded that an individual's risk of atherosclerotic disease is strongly determined by their cumulative lifelong exposure to LDL-C [1].

\footnotetext{
* Correspondence: maciejbanach77@gmail.com

Recommendations endorsed by the International Lipid Expert Panel (ILEP; ilep.eu)

${ }^{5}$ Department of Hypertension, Medical University of Lodz, Rzgowska 281/289,

93-338 Lodz, Poland

${ }^{6}$ Polish Mother's Memorial Hospital Research Institute (PMMHRI), Lodz, Poland

Full list of author information is available at the end of the article
}

Accordingly, a significant long-term increased risk for coronary heart disease (CHD) and cardiovascular mortality has been reported in young adults with LDL-C $\geq 100 \mathrm{mg} / \mathrm{dL}(2.5 \mathrm{mmol} / \mathrm{L})[2,3]$. Therefore, in order to prevent atherosclerosis and its sequelae (myocardial infarction, ischemic stroke and peripheral arterial disease), it is necessary to act early in life. Indeed, the early manifestations of atherosclerosis are often apparent in the third decade of life [4-7], a problem that is brought into stark reality by the early morbidity and mortality associated with familial hypercholesterolaemia (FH) [8]. Moreover, changes in plasma cholesterol levels have been found to be directly associated with cardiovascular disease (CVD) events in young adults [9]. Based on these findings, it is clear that, with respect to LDL-C, 'lower is better, for longer'.

\section{Main text}

The risk of atherosclerotic CVD events and mortality can be reduced by currently used drugs, which reduce

(c) The Author(s). 2020 Open Access This article is licensed under a Creative Commons Attribution 4.0 International License which permits use, sharing, adaptation, distribution and reproduction in any medium or format, as long as you give appropriate credit to the original author(s) and the source, provide a link to the Creative Commons licence, and indicate if changes were made. The images or other third party material in this article are included in the article's Creative Commons licence, unless indicated otherwise in a credit line to the material. If material is not included in the article's Creative Commons licence and your intended use is not permitted by statutory regulation or exceeds the permitted use, you will need to obtain permission directly from the copyright holder. To view a copy of this licence, visit http://creativecommons.org/licenses/by/4.0/ The Creative Commons Public Domain Dedication waiver (http://creativecommons.org/publicdomain/zero/1.0/) applies to the data made available in this article, unless otherwise stated in a credit line to the data. 
circulating concentrations of LDC. These include statins (which inhibit HMG-CoA reductase, the rate-limiting step in hepatic endogenous cholesterol synthesis) [10-12], ezetimibe (which inhibits the polytopic transmembrane protein, Niemann-Pick C1-Like 1, which is responsible for cholesterol absorption from the jejunal brush border) [13], and anti-proprotein convertase subtilisin/kexin type 9 (PCSK9) monoclonal antibodies (which inhibit PCSK9, a regulatory protein that binds to LDL-receptors on hepatocytes and promotes their routing into lysosomes for proteolytic destruction) $[14,15]$. Intriguingly, inhibition of HMG-CoA reductase, Niemann-Pick C1-Like 1 and PCSK9 all increase the LDL-receptor density on the surface of hepatocytes, which results in more extensive removal of circulating LDL particles.

Because of the multifactorial nature of risk factors predisposing to CVD, and in order to use lipid-lowering drugs most effectively, reducing unnecessary cost and exposure to adverse effects, national and international guidelines make recommendations relating to the initiation of lipid-lowering therapy based upon calculations of cardiovascular risk, rather than lipid profile alone. Although the specifics of the risk prediction tools and thresholds differ between major guidelines, the approach is essentially the same. The European Society of Cardiology (ESC)/European Atherosclerosis Society (EAS) [16] recommendations are based upon the SCORE 10year risk calculation [17] and consider both the overall SCORE and the untreated circulating LDL-C concentration in determining whether drug interventions should be employed [16]. In the UK, NICE recommends offering lipid modification therapy to people aged 84 years and younger if their estimated 10-year risk of developing CVD using the QRISK [18] assessment tool is $10 \%$ or more and lifestyle modification is ineffective or inappropriate [19]. American College of Cardiology (ACC)/ American Heart Association (AHA) guidelines recommend statin therapy when 10-year risk, calculated using the pooled-cohort equations [20] exceeds 7.5\% [21] (for non-diabetics with LDL-C $>70 \mathrm{mg} / \mathrm{dL}$ [1.8 $\mathrm{mmol} / \mathrm{L}]$ and the presence of other risk enhancing factors).

However, 10-year predictions underestimate lifetime risk and are driven to a large extent by age [22, 23]. Clinical guidelines based upon 10-year risk profiles are prone to ignore younger patients with a single risk factor, which is unlikely to result in deleterious outcomes in the forthcoming decade, but which epidemiological evidence suggests is associated with an elevated incidence of disease later in life [24]. This is perhaps justifiable for non-modifiable risk factors, but when multiple strategies exist to ameliorate the associated risk, as they do for LDL-C, then we are at risk of missing opportunities to intervene now to improve health in later life.
There is considerable inconsistency in approaches used to manage patients at overall low risk of CVD (<1\%) who have persistently elevated levels of LDL-C (115 mg/dL [3 mmol/L]-190 mg/dL [4.9 mmol/L]). In the 2016 ESC/EAS guidelines for the management of dyslipidaemias, no intervention was recommended until LDL-C reached $190 \mathrm{mg} / \mathrm{dL}(4.9 \mathrm{mmol} / \mathrm{L})$ [25], which was a matter of considerable debate and presented problems in everyday clinical practice. In the 2019 recommendations, lifestyle modifications are suggested initially, and pharmacological interventions can be now considered for individuals with LDL-C above $115 \mathrm{mg} / \mathrm{dL}$ ( $3 \mathrm{mmol} / \mathrm{L})$ [16].

We propose a more detailed approach to the management of cardiovascular risks in individuals with low (<1\%) 10-year risk of CVD, but elevated (>140 mg/dL, $3.6 \mathrm{mmol} / \mathrm{L}$ ) LDL-C (Fig. 1). The cutoff point of $140 \mathrm{mg} /$ $\mathrm{dL}(3.6 \mathrm{mmol} / \mathrm{L})$ results from the calculations of the possibility of LDL-C reduction to the target level of $115 \mathrm{mg} /$ $\mathrm{dL}(3 \mathrm{mmol} / \mathrm{L})$ with the adherent lifestyle changes; this level also appeared in the previous 2017 ESC/EAS task force on practical clinical guidance for PCSK9 inhibitors application in patients with atherosclerotic CVD, where the persistent LDL-C level of $>140 \mathrm{mg} / \mathrm{dL}(3.6 \mathrm{mmol} / \mathrm{L}$; on statins and ezetimibe) was an independent risk factor linked to significantly increased CVD risk, requiring consideration of PCSK9 inhibitors [26]. The strategy proposed in this paper is largely based upon evidencebased interventions to reduce LDL-C, rather than the ideal endpoints of major adverse cardiovascular events (MACE) and mortality. In this regard, the strong-graded relationship between LDL-C and mortality seen across many hundreds of studies [1], and the availability of very large well-conducted epidemiological datasets means that it is appropriate to base recommendations on studies employing LDL-C reduction as the primary endpoint. The potential benefits of this approach are highlighted by a recent study which quantified the relative importance of risk factors for CHD. Amongst a population of 22,626 individuals, aged 45-85, the population attributable fraction (PAF) was found to be $17 \%$ (95\% CI $10.2-$ 23.2) for non-HDL-C $>130 \mathrm{mg} / \mathrm{dl}$. However, in the subpopulation of individuals aged 45-54, the PAF was $32.8 \%$ (95\% CI 10.1-49.9), suggesting a large proportion of coronary heart disease might be eliminated by optimal lipid-management in younger individuals [27].

The first and most important approach to low 10-year risk individuals is to provide education and information relating to the benefits of lifestyle interventions (LSI). The dietary approach to LDL-C reduction includes the promotion of a well-balanced diet, which derives a low proportion of energy from saturated fatty acids [28], and a high proportion from polyunsaturated fatty acids [29]. ESC/EAS guidelines suggest that carbohydrate intake 


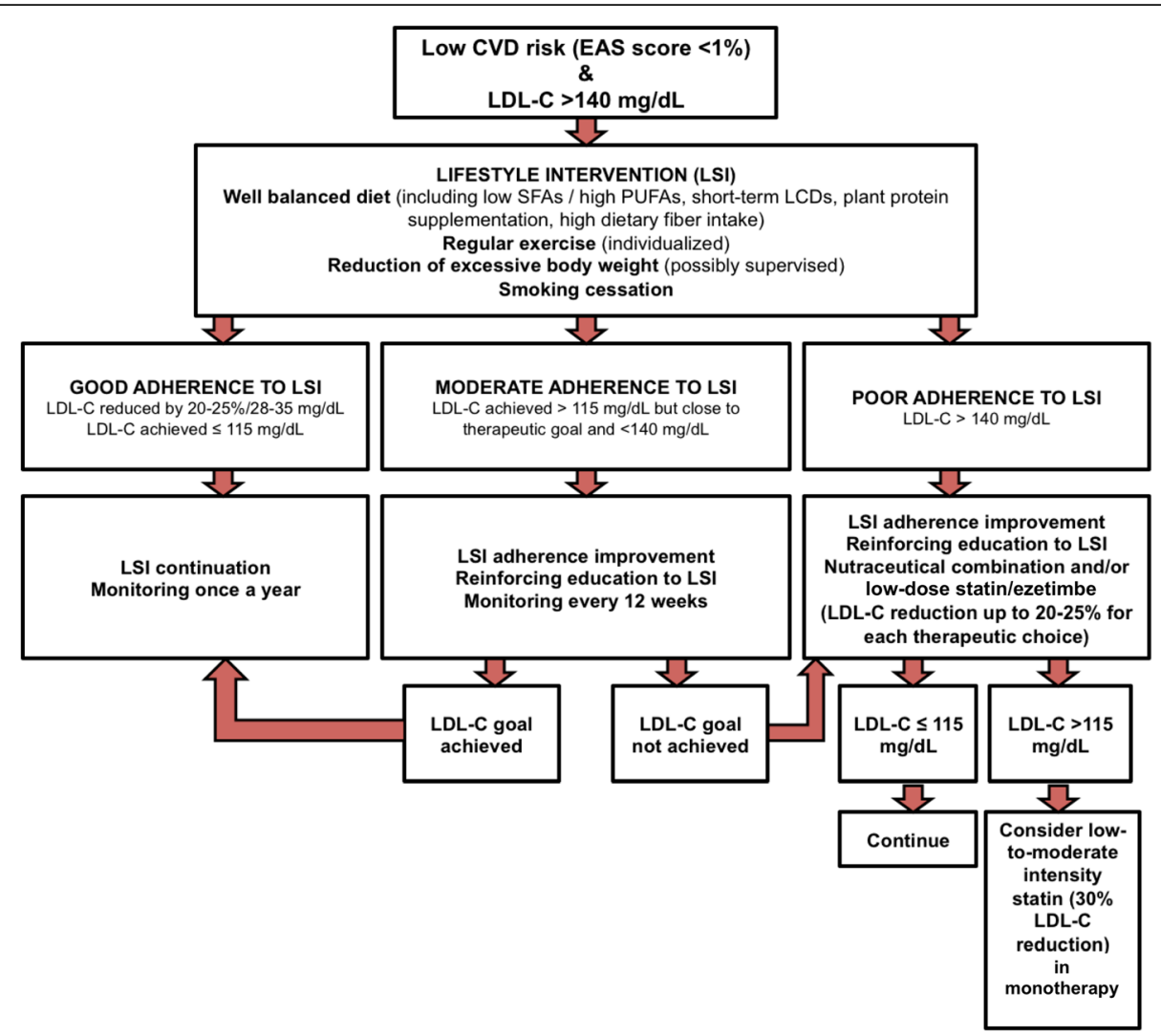

Fig. 1 Proposed approach to the management of cardiovascular risks in individuals with low $(<1 \%)$ 10-year risk of cardiovascular disease, but elevated (> $140 \mathrm{mg} / \mathrm{dL}, 3.6 \mathrm{mmol} / \mathrm{L}$ ) LDL-C

should range between 45 and $55 \%$ of total energy intake and that intake of added sugar should not exceed $10 \%$ of total energy [16]. In the short-term, low-carbohydrate diets (LCD) [30] improve lipid profile, although a recent well-designed investigation found a potentially unfavourable association of LCD with overall and cause-specific mortality, based on both analyses of an established cohort and by pooling previous cohort studies in a metaanalysis [31, 32]. Dietary fibre (particularly when it replaces saturated fat in the diet) has beneficial effects on plasma lipid profile [33]. The benefits of smoking cessation [34], exercise [35], and weight reduction [35], on cardiovascular risk, are more closely associated with elevation of HDL-C and reduction of triglycerides, than reduction of LDL-C, but these strategies should nevertheless be encouraged in all individuals, especially those with any risk factors for CVD [16, 25].

For those individuals who manage good adherence to LSI (indicated by a reduction of LDL-C by $20-25 \% / 28-$ $35 \mathrm{mg} / \mathrm{dl}=$ achieved $\quad \mathrm{LDL}-\mathrm{C} \leq 115 \mathrm{mg} / \mathrm{dL} \quad[3 \mathrm{mmol} / \mathrm{L}]$ ), annual check-up to monitor cardiovascular risk and reinforce messages about LSI are appropriate. For individuals with moderate success at reducing LDL-C using LSI (indicated by LDL-C $>115 \mathrm{mg} / \mathrm{dL}$ [ $3 \mathrm{mmol} / \mathrm{L}]$ but close to target and $<140 \mathrm{mg} / \mathrm{dL}[3.6 \mathrm{mmol} / \mathrm{L}])$, more frequent monitoring (preferably every 12 weeks) is appropriate, and these individuals may benefit from enhanced educational interventions. Where adherence to LSI is poor (indicated by LDL-C $>140 \mathrm{mg} / \mathrm{dL}$ [3.6 $\mathrm{mmol} / \mathrm{L}]$ ), nutraceuticals/nutraceutical combination [36] and/or low-dose statin therapy and/or ezetimibe (especially in those with statin-related muscle symptoms or not willing to use statins) in combination with continued LSI might be warranted in order to reach the recommended LDL-C goals. This three-arm practical management is based on the real-world adherence to lifestyle changes, which is usually only $25-30 \%$, and even worse in patients in primary prevention [37, 38]. Real-world adherence to lipid-lowering therapy is also suboptimal and poor adherence is associated with worse CVD outcomes [39].

Recent position papers produced by the International Lipid Expert Panel [40-42] and other Scientific Societies [43] have summarised the evidence relating to the cholesterol-lowering effects of nutraceuticals in general $[41,42]$ and in the specific situation of statin intolerance [40]. A wide range of nutraceuticals, alone or in combination therapy, have been shown to have favourable 
effects on lipid profiles. However, nutraceuticals are often evaluated in much smaller studies than phase 3 evaluations of conventional pharmaceuticals. Furthermore, variation in product composition between different preparations of similarly named nutraceuticals can lead to heterogeneity of response. Thus, the evidence basis for the safety and efficacy of nutraceuticals is generally less strong than conventional pharmaceuticals. The role of nutraceuticals should not be to replace conventional pharmaceuticals in settings where they have been shown to be effective, but to optimise treatment when lipid targets are not met. Lipid-lowering nutraceuticals include red yeast rice (with confirmed production quality/citrinin-free), bergamot, berberine, policosanol, artichoke, soluble fibre, and plant sterols and stanols $[40,44]$. Although the LDL-C reductions elicited by these agents are generally modest compared with highintensity statins and PCSK9-inhibitors, nevertheless, the 'lower is better for longer' approach to cardiovascular risk-reduction implies that a small reduction of LDL-C sustained over a long period of time would be expected to accrue a substantial benefit in terms of CVD risk reduction. This latter interpretation is supported by the observation that ezetimibe therapy, despite producing a relatively mild LDL-C lowering, also caused a significant reduction of CVD risk [13, 45]. Finally, when LDL-C remains $>115 \mathrm{mg} / \mathrm{dl}(3.0 \mathrm{mmol} / \mathrm{L})$, despite LSI, and eventually nutraceuticals, statin and/or ezetimibe [41, 45] therapy should be considered. In the opinion of the authors, there is no need for a more intensive approach for low-risk patients, particularly as we do not have enough data on the effectiveness of such an approach in reducing CVOT. Furthermore, the potential for increased risk of statin-related adverse effects would clearly not be desirable and might influence the effectiveness of later therapy in this group of patients.

\section{Conclusions}

In summary, even mild LDL-C elevations at a young age elevate CVD risk and are likely to have a greater unfavourable prognostic impact than similar elevations in older individuals, as has been recently confirmed [46]. Commonly used 10-year CVD risk scores are insufficiently sensitive to detect long-term CV risk in younger individuals. The recent recommendation by the ACC/ AHA [21] to use lifetime risk scores in younger patients is pragmatic and sensible. The use of systems highlighting the long-term $\mathrm{CV}$ risk in younger individuals is desirable $[47,48]$, and practical strategies combining LSI, nutraceuticals, statins, and ezetimibe (as proposed in this commentary) should be used to modify elevated lifetime risk when it is detected. With respect to LDL-C, we know that 'lower is better for longer'; therefore, we must allow this knowledge to be used to help those subjects (currently) at 'low CVD risk'. Individuals who undertake approaches to reduce lipids at a lower age can benefit from a lower life-long exposure to LDL-C.

It is also important to emphasise that the unmet need for prevention and suitable treatment for these patients is likely to grow (with increasing numbers of such patients in the everyday clinical practice). Additionally, because of the paucity of data, well-designed studies are still necessary in order to answer the questions on the efficacy, safety, and cost-effectiveness of long-term interventions to reduce LDL-C in low-risk populations. Moreover, with the suggested approach, which is driven by changes in lifestyle, we emphasise the critical importance of non-pharmacological interventions, not only for those at high and very high risk, but equally (or, perhaps, more importantly) for those at low cardiovascular risk.

\section{Abbreviations}

CHD: Coronary heart disease; CVD: Cardiovascular disease; EAS: European Atherosclerosis Society; ESC: European Society of Cardiology; HDL-C: Highdensity lipoprotein-cholesterol; HMG CoA: 3-Hydroxy-3-methyl-glutaryl-CoA; LCD: Low-carbohydrate diet; LDL: Low-density lipoprotein; LDL-C: Lowdensity lipoprotein-cholesterol; LSI: Lifestyle interventions; MACE: Major adverse cardiovascular events; PAF: Population attributable fraction; PCSK9: Proprotein convertase subtilisin/kexin type 9

\section{Acknowledgements \\ This opinion was written independently; no company or institution supported it financially. No professional writer was involved in the preparation of this position paper.}

\section{Authors' contributions}

Conceptualization, M.B.; methodology (literature search), M.B., P. P, M.P.; writing-original draft preparation, P.P.; writing-review and editing, M.B., P.P., M.P.; supervision, M.B. All authors have read and agreed to the published version of the manuscript.

\section{Funding}

None.

Availability of data and materials

Not applicable

Ethics approval and consent to participate Not applicable

\section{Consent for publication}

Not applicable

\section{Competing interests}

PEP owns four shares in AstraZeneca PLC and has received honoraria and/or travel reimbursement for events sponsored by AKCEA, Amgen, AMRYT, Link Medical, Napp, Sanofi; MP has received honoraria and/or travel reimbursement for events sponsored by Amgen, Alfasigma, Mylan, Neopharmed Gentili, Sanofi; MB - speakers bureau: Abbott/Mylan, Akcea, Amgen, Daichii Sankyo, KRKA, MSD, Novartis, Novo-Nordisk, Polpharma, Sanofi, Servier; consultant to Akcea, Amgen, Daichii Sankyo, Esperion, Freia Pharmaceuticals, MSD, Polfarmex, Resverlogix, Sanofi/Regeneron; Grants from Amgen, Mylan, Sanofi, and Valeant.

\section{Author details}

${ }^{1}$ School of Pharmacy and Biomolecular Sciences, Liverpool John Moores University, Liverpool, UK. 'Liverpool Centre For Cardiovascular Science, Liverpool, UK. ${ }^{3}$ University of Liverpool, Liverpool, UK. ${ }^{4}$ Unit of Internal Medicine, Angiology and Arteriosclerosis Diseases, Department of Medicine, University of Perugia, Perugia, Italy. ${ }^{5}$ Department of Hypertension, Medical 
University of Lodz, Rzgowska 281/289, 93-338 Lodz, Poland. 'Polish Mother's Memorial Hospital Research Institute (PMMHRI), Lodz, Poland. ${ }^{7}$ Cardiovascular Research Centre, University of Zielona Gora, Zielona Gora, Poland.

Received: 12 March 2020 Accepted: 23 September 2020 Published online: 08 October 2020

\section{References}

1. Ference BA, Ginsberg HN, Graham I, Ray KK, Packard CJ, Bruckert E, Hegele RA, Krauss RM, Raal FJ, Schunkert H, et al. Low-density lipoproteins cause atherosclerotic cardiovascular disease. 1. Evidence from genetic, epidemiologic, and clinical studies. A consensus statement from the European Atherosclerosis Society Consensus Panel. Eur Heart J. 2017:38(32): 2459-72.

2. Zhang $Y$, Vittinghoff $E$, Pletcher MJ, Allen NB, Zeki Al Hazzouri A, Yaffe K, Balte PP, Alonso A, Newman AB, Ives DG, et al. Associations of blood pressure and cholesterol levels during young adulthood with later cardiovascular events. J Am Coll Cardiol. 2019;74(3):330-41.

3. Abdullah SM, Defina LF, Leonard D, Barlow CE, Radford NB, Willis BL, Rohatgi A, McGuire DK, de Lemos JA, Grundy SM, et al. Long-term association of low-density lipoprotein cholesterol with cardiovascular mortality in individuals at low 10-year risk of atherosclerotic cardiovascular disease. Circulation. 2018;138(21):2315-25.

4. Virmani R, Robinowitz M, Geer JC, Breslin PP, Beyer JC, McAllister HA Coronary artery atherosclerosis revisited in Korean war combat casualties. Arch Pathol Lab Med. 1987:111(10):972-6.

5. McNamara JJ, Molot MA, Stremple JF, Cutting RT. Coronary artery disease in combat casualties in Vietnam. JAMA. 1971;216(7):1185-7.

6. Joseph A, Ackerman D, Talley JD, Johnstone J, Kupersmith J. Manifestations of coronary atherosclerosis in young trauma victims--an autopsy study. J Am Coll Cardiol. 1993;22(2):459-67.

7. Enos WF Jr, Beyer JC, Holmes RH. Pathogenesis of coronary disease in American soldiers killed in Korea. J Am Med Assoc. 1955;158(11):912-4.

8. Miettinen TA, Gylling H. Mortality and cholesterol metabolism in familial hypercholesterolemia. Long-term follow-up of 96 patients. Arteriosclerosis. 1988;8(2):163-7

9. Jeong SM, Choi S, Kim K, Kim SM, Lee G, Park SY, Kim YY, Son JS, Yun JM, Park SM: Effect of change in total cholesterol levels on cardiovascular disease among young adults. J Am Heart Assoc. 2018;7(12):e008819.

10. Scandinavian Simvastatin Survival Study Group: Randomised trial of cholesterol lowering in 4444 patients with coronary heart disease: the Scandinavian Simvastatin Survival Study (4S). Lancet. 1994;344(8934):1383-9.

11. Shepherd J, Cobbe SM, Ford I, Isles CG, Lorimer AR, MacFarlane PW, McKillop JH, Packard CJ. Prevention of coronary heart disease with pravastatin in men with hypercholesterolemia. West of Scotland Coronary Prevention Study Group. N Engl J Med. 1995:333(20):1301-7.

12. Collins R, Reith C, Emberson J, Armitage J, Baigent C, Blackwell L, Blumenthal R, Danesh J, Smith GD, DeMets D, et al. Interpretation of the evidence for the efficacy and safety of statin therapy. Lancet. 2016; 388(10059):2532-61

13. Cannon CP, Blazing MA, Giugliano RP, McCagg A, White JA, Theroux $P$ Darius H, Lewis BS, Ophuis TO, Jukema JW, et al. Ezetimibe added to statin therapy after acute coronary syndromes. N Engl J Med. 2015;372(25):2387-97.

14. Sabatine MS, Giugliano RP, Keech AC, Honarpour N, Wiviott SD, Murphy SA, Kuder JF, Wang H, Liu T, Wasserman SM, et al. Evolocumab and clinical outcomes in patients with cardiovascular disease. N Engl J Med. 2017; 376(18):1713-22

15. Schwartz GG, Steg PG, Szarek M, Bhatt DL, Bittner VA, Diaz R, Edelberg JM, Goodman SG, Hanotin C, Harrington RA, et al. Alirocumab and cardiovascular outcomes after acute coronary syndrome. N Engl J Med. 2018;379(22):2097-107.

16. Mach F, Baigent C, Catapano AL, Koskinas KC, Casula M, Badimon L, Chapman MJ, De Backer GG, Delgado V, Ference BA, et al. ESC/EAS guidelines for the management of dyslipidaemias: lipid modification to reduce cardiovascular risk. Eur Heart J. 2020;41(1):111-188.

17. Piepoli MF, Hoes AW, Agewall S, Albus C, Brotons C, Catapano AL, Cooney MT, Corra U, Cosyns B, Deaton C, et al. 2016 European Guidelines on cardiovascular disease prevention in clinical practice: The Sixth Joint Task Force of the European Society of Cardiology and Other Societies on Cardiovascular Disease Prevention in Clinical Practice (constituted by representatives of 10 societies and by invited experts): Developed with the special contribution of the European Association for Cardiovascular Prevention \& Rehabilitation (EACPR). Eur J Prev Cardiol. 2016;23(11):NP1NP96.

18. Hippisley-Cox J, Coupland C, Brindle P. Development and validation of QRIS $\mathrm{K} 3$ risk prediction algorithms to estimate future risk of cardiovascular disease: prospective cohort study. BMJ. 2017:357:j2099.

19. National Institute for Health and Care Excellence (NICE): Cardiovascular disease risk assessment and reduction including lipid modification. CG181 2014:1-44.

20. Goff DC, Lloyd-Jones DM, Bennett G, Coady S, D'Agostino RB, Gibbons R, Greenland P, Lackland DT, Levy D, O'Donnell CJ, et al. 2013 ACC/AHA guideline on the assessment of cardiovascular risk. J Am Coll Cardiol. 2014; 63(25):2935-59.

21. Arnett DK, Blumenthal RS, Albert MA, Buroker AB, Goldberger ZD, Hahn EJ, Himmelfarb CD, Khera A, Lloyd-Jones D, McEvoy JW, et al. 2019 ACC/AHA guideline on the primary prevention of cardiovascular disease: a report of the American College of Cardiology/American Heart Association Task Force on Clinical Practice Guidelines. J Am Coll Cardiol. 2019;74(10):e177-232.

22. Jeemon P, Prabhakaran D, Huffman MD, Ramakrishnan L, Goenka S, Thankappan KR, Mohan V, Joshi PP, Mohan BV, Ahmed F, et al. Distribution of 10-year and lifetime predicted risk for cardiovascular disease in the Indian Sentinel Surveillance Study population (cross-sectional survey results). BMJ Open. 2011;1(1):e000068.

23. Marma AK, Berry JD, Ning H, Persell SD, Lloyd-Jones DM. Distribution of 10year and lifetime predicted risks for cardiovascular disease in US adults: findings from the National Health and Nutrition Examination Survey 2003 to 2006. Circ Cardiovasc Qual Outcomes. 2010;3(1):8-14.

24. Pencina MJ, D'Agostino RB Sr, Larson MG, Massaro JM, Vasan RS. Predicting the 30-year risk of cardiovascular disease: the Framingham heart study. Circulation. 2009:119(24):3078-84

25. Catapano AL, Graham I, De Backer G, et al. ESC Scientific Document Group. 2016 ESC/EAS Guidelines for the Management of Dyslipidaemias. Eur Heart J. 2016;37(39):2999-3058

26. Landmesser U, Chapman MJ, Stock JK, et al. 2017 Update of ESC/EAS Task Force on practical clinical guidance for proprotein convertase subtilisin/ kexin type 9 inhibition in patients with atherosclerotic cardiovascular disease or in familial hypercholesterolaemia. Eur Heart J. 2018;39(14):1131-43.

27. Pencina MJ, Navar AM, Wojdyla D, Sanchez RJ, Khan I, Elassal J, D'Agostino RB Sr, Peterson ED, Sniderman AD. Quantifying importance of major risk factors for coronary heart disease. Circulation. 2019;139(13):1603-11.

28. Mensink RP, Zock PL, Kester AD, Katan MB. Effects of dietary fatty acids and carbohydrates on the ratio of serum total to $\mathrm{HDL}$ cholesterol and on serum lipids and apolipoproteins: a meta-analysis of 60 controlled trials. Am J Clin Nutr. 2003;77(5):1146-55.

29. Schwingshackl L, Bogensberger B, Bencic A, Knuppel S, Boeing H, Hoffmann G. Effects of oils and solid fats on blood lipids: a systematic review and network meta-analysis. J Lipid Res. 2018;59(9):1771-82.

30. Gjuladin-Hellon T, Davies IG, Penson P, Amiri BR. Effects of carbohydraterestricted diets on low-density lipoprotein cholesterol levels in overweight and obese adults: a systematic review and meta-analysis. Nutr Rev. 2019; 77(3):161-80.

31. Mazidi M, Katsiki N, Mikhailidis DP, Sattar N, Banach M. Lower carbohydrate diets and all-cause and cause-specific mortality: a population-based cohort study and pooling of prospective studies. Eur Heart J. 2019;40(34):2870-9.

32. Banach M, Mikhailidis DP, Mazidi M. Low-carbohydrate diet: forget restriction, replace with balance! Eur Heart J. 2019. https://doi.org/10.1093/ eurheartj/ehz927.

33. Brown L, Rosner B, Willett WW, Sacks FM. Cholesterol-lowering effects of dietary fiber: a meta-analysis. Am J Clin Nutr. 1999;69(1):30-42.

34. Maeda K, Noguchi Y, Fukui T. The effects of cessation from cigarette smoking on the lipid and lipoprotein profiles: a meta-analysis. Prev Med 2003;37(4):283-90.

35. Kraus WE, Houmard JA, Duscha BD, Knetzger KJ, Wharton MB, McCartney JS, Bales CW, Henes S, Samsa GP, Otvos JD, Kulkarni KR, Slentz CA. Effects of the amount and intensity of exercise on plasma lipoproteins. N Engl J Med. 2002;347(19):1483-92.

36. Sosnowska B, Penson $P$, Banach $M$. The role of nutraceuticals in the prevention of cardiovascular disease. Cardiovasc Diagn Ther. 2017;7(Suppl 1):S21-31.

37. Stonerock GL, Blumenthal JA. Role of counseling to promote adherence in healthy lifestyle medicine: strategies to improve exercise adherence and enhance physical activity. Prog Cardiovasc Dis. 2017;59(5):455-62. 
38. Booth JN 3rd, Colantonio LD, Howard G, Safford MM, Banach M, Reynolds K, Cushman M, Muntner P. Healthy lifestyle factors and incident heart disease and mortality in candidates for primary prevention with statin therapy. Int J Cardiol. 2016;207:196-202.

39. Serban MC, Colantonio LD, Manthripragada AD, Monda KL, Bittner VA, Banach M, Chen L, Huang L, Dent R, Kent ST, et al. Statin intolerance and risk of coronary heart events and all-cause mortality following myocardial infarction. J Am Coll Cardiol. 2017;69(11):1386-95.

40. Banach M, Patti AM, Giglio RV, et al. International Lipid Expert Panel. The role of nutraceuticals in statin intolerant patients. J Am Coll Cardiol. 2018; 72(1):96-118.

41. Cicero AFG, Colletti A, Bajraktari G, et al. Lipid lowering nutraceuticals in clinical practice: position paper from an International Lipid Expert Panel. Arch Med Sci. 2017;13(5):965-1005.

42. Cicero AFG, Colletti A, Bajraktari G, et al. Lipid-lowering nutraceuticals in clinical practice: position paper from an International Lipid Expert Panel. Nutr Rev. 2017;75(9):731-67.

43. Pirro M, Vetrani C, Bianchi C, Mannarino MR, Bernini F, Rivellese AA. Joint position statement on "Nutraceuticals for the treatment of hypercholesterolemia" of the Italian Society of Diabetology (SID) and of the Italian Society for the Study of Arteriosclerosis (SISA). Nutr Metab Cardiovasc Dis. 2017;27(1):2-17.

44. Morze J, Osadnik T, Osadnik K, Lejawa M, Jakubiak G, Pawlas N, Gasior M, Schwingschackl L, Banach M. A network meta-analysis on the comparative efficacy of nutraceuticals on lipid profile. Circulation. 2019;140:A13360.

45. Ouchi Y, Sasaki J, Arai H, et al. Ezetimibe lipid-lowering trial on prevention of atherosclerotic cardiovascular disease in 75 or older (EWTOPIA 75): a randomized, controlled trial. Circulation. 2019;140:992-1003.

46. Wang N, Fulcher J, Abeysuriya N, et al. Intensive LDL cholesterol-lowering treatment beyond current recommendations for the prevention of major vascular events: a systematic review and meta-analysis of randomised trials including 327037 participants. Lancet Diabetes Endocrinol. 2020;8:36-49.

47. Lloyd-Jones DM, Leip EP, Larson MG, D'Agostino RB, Beiser A, Wilson PW, Wolf PA, Levy D. Prediction of lifetime risk for cardiovascular disease by risk factor burden at 50 years of age. Circulation. 2006:113:791-8.

48. Michos ED, McEvoy JW, Blumenthal RS. Lipid management for the prevention of atherosclerotic cardiovascular disease. N Engl J Med. 2019;381; 1557-67.

\section{Publisher's Note}

Springer Nature remains neutral with regard to jurisdictional claims in published maps and institutional affiliations.

Ready to submit your research? Choose BMC and benefit from:

- fast, convenient online submission

- thorough peer review by experienced researchers in your field

- rapid publication on acceptance

- support for research data, including large and complex data types

- gold Open Access which fosters wider collaboration and increased citations

- maximum visibility for your research: over $100 \mathrm{M}$ website views per year

At BMC, research is always in progress.

Learn more biomedcentral.com/submissions 